\title{
Aspectos que influenciam a maciez da carne de bovinos: Revisão
}

\author{
Egon Henrique Horst ${ }^{1 *}$, Mikael Neumann², Guilherme Fernando Mattos Leão ${ }^{3}$, Juliana \\ Mareze $^{4}$, Marcelle Mareze ${ }^{5}$, André Dochwat ${ }^{6}$ Robson Kyoshi Ueno ${ }^{7}$
}

${ }^{I}$ Mestrando em Agronomia na Universidade Estadual do Centro Oeste - UNICENTRO, Guarapuava-PR. E-mail: egonhh@yahoo.com.br 2Prof. Dr. do departamento de Medicina Veterinária da Universidade Estadual do Centro Oeste - UNICENTRO, Guarapuava - PR. E-mail: mikaelneumann@hotmail.com

${ }^{3}$ Mestrando em Zootecnia na Universidade Estadual de Maringá - UEM, Maringá, PR. E-mail: gfleao@ hotmail.com.

${ }^{4}$ Mestranda em Medicina Veterinária na Universidade Estadual de Londrina - UEL, Londrina, PR. E-mail: juliana_mareze@hotmail.com

${ }^{5}$ Mestranda em Ciência Animal da Universidade Estadual de Londrina/UEL. E-mail: marcelle_mareze@hotmail.com

${ }^{6}$ Acadêmico Medicina Veterinária da Universidade Estadual do Centro-Oeste do Paranál UNICENTRO. E-mail: andre.dochwat@hotmail.com

${ }^{7}$ Doutorando em Zootecnia pela Universidade Federal do Rio Grande do Sul-UFRGS, Porto Alegre, RS. E-mail: robsonueno@ hotmail.com

*Autor para correspondência

RESUMO. Os consumidores estão cada vez mais exigentes em relação a qualidade da carne consumida em virtude do aumento da renda per capita. Todavia, o padrão cárneo brasileiro possui diversos entraves sob tal ótica. Desta forma, esta revisão de literatura visa abordar as principais diferenças da carcaça e da carne de bovinos sob diferentes sistemas de terminação.

Palavras chave: Confinamento, idade ao abate, marmoreio

\section{Aspects that influence the tenderness cattle meat: Review}

\begin{abstract}
Consumers are becoming increasingly demanding for meat quality due to the increased of the per capita income. However, the Brazilian meat pattern has a lot of problems on these circumstances. So, this review approaches the main differences of carcass and cattle meat in different finishing systems.
\end{abstract}

Keywords: feedlot, slaughter age, marbling

\section{Introdução}

O Brasil possui o maior rebanho comercial do mundo e é o segundo maior produtor mundial de carne bovina. (FAPRI, 2015). Por isso, a bovinocultura vem ganhando destaque na economia nacional (Prado, 2010a). Contudo, no aspecto de rentabilidade o produto nacional deixa a desejar, pois tende a ser menos remunerado pelo mercado internacional devido à inconstância em termos produtivos e qualitativos, voltados somente para uma visão extensiva e pouco gerencial. Em termos de qualidade, a carne bovina nacional está aquém do desejado, pela falta de padronização que apresenta (Ferraz \& Felício, 2010). A qualidade do produto é relevante, pois os consumidores estão cada vez mais conscientes e capitalizados. A criação de novos nichos de mercados está cada vez mais voltada à qualidade dos produtos oferecidos (Maciel et al., 2011).

Deve-se deixar claro que o conceito de qualidade de um produto alimentício, como é o caso da carne bovina, é extremamente amplo e ligado a uma série de fatores como a segurança alimentar, responsabilidade social e ambiental, bem-estar animal, além da qualidade intrínseca propriamente dita (Hocquette et al., 2005).

Existe uma grande discussão sobre os sistemas de terminação e como este pode influenciar a qualidade da carne (Prado, 2010a). A exemplo, Prado (2010b) esclarece que, bovinos submetidos a dietas em confinamento tendem a melhoras na produtividade e na qualidade da carne se comparados a bovinos terminados a pasto. Segundo o autor, a redução da idade de abate é o fator determinante para tal, já que animais mais jovens possuem maior eficiência alimentar. Concomitante a isto, os altos níveis energéticos das dietas tendem a promoverem melhor acabamento da carcaça.

Essa revisão literária irá abordar os fatores que afetam as características e a qualidade da 
carcaça e da carne de bovinos terminados em condições e dietas diferentes.

\section{Desenvolvimento}

Ao se classificar uma carne, os atributos de qualidade são ponderados em qualidade visual, nutricional, gustativa e segurança alimentar (Guerrero et al., 2013). De forma prática, a qualidade de uma carcaça depende de fatores que antecedem o abate (intrínsecos), sendo estes vinculados ao genótipo e as condições ambientais nas quais esses animais se desenvolveram, e ainda aos fatores pós-abate (extrínsecos) (Guerrero et al., 2013). Dentre os principais fatores intrínsecos que alteram expressivamente a qualidade da carne, pode-se destacar a genética do animal (raça/cruzamento), o sexo, a idade ao abate e a nutrição (Rotta et al., 2009).

\section{Genética}

Levando em consideração o parâmetro maciez, cerca de $15 \%$ depende das diferenças em gordura intramuscular e colágeno de cada animal. Além disto, outro ponto seria que a velocidade e extensão da proteólise no momento de conversão do músculo em carne também têm grande influência genética. Já os $85 \%$ restantes podem ser atribuídos às variações no processo enzimático que leva à maturação da carne bovina (Koohmaraie et al., 1994). Por exemplo, a carne de animais Bos taurus passa por um processo de maturação nas 24 primeiras horas post mortem, enquanto a de Bos indicus têm um processo mais lento, assim, quanto maior a participação de Bos indicus no genótipo, menor a velocidade e a extensão dos efeitos da maturação (Whipple et al., 1990).

Crouse et al. (1989) relataram que a participação de Bos indicus $(0,25,50$ e $75 \%$ Brahman ou Sahiwal) nos cruzamentos resultou em carne mais dura, quando comparados aos mestiços de raças britânicas, com média de força de cisalhamento do músculo Longissimus dorsi, de $4,4 \mathrm{~kg}$, onde os mestiços 1/4, 1/2 e 3/4 Brahman ou Sahiwal apresentaram médias de $5,2,5,8$ e $6,7 \mathrm{~kg}$ ou 5,6, 6,6 e 8,4 $\mathrm{kg}$ de força de cisalhamento, respectivamente. A explicação biológica para $\mathrm{o}$ fato é a maior atividade bioquímica de um fator inibidor de proteases cálcio-dependentes nos zebuínos. Tal fator inibe a degradação de algumas proteínas miofibrilares, retardando a maturação da carne de Bos indicus (Hocquette et al., 2007).
Todas as células de mamíferos contêm esse sistema proteolítico dependente de cálcio, composto pela protease endógena calpaína e seu inibidor, a calpastatina (Goll, 1992). A calpaína está presente no citosol como uma forma inativa e quando há aumento no cálcio realiza um processo autoproteolítico (Geesink et al., 2006). A calpastatina é inibidor específico da calpaína. A calpastatina pode impedir a ativação autoproteolítica, a translocação da membrana e a expressão da atividade catalítica da calpaína (Lee et al., 1992).

Sexo

Dentre as técnicas para melhorar a qualidade da carcaça e o manejo dos bovinos a pasto, destinados à produção de carne, a castração tem sido ainda objeto de estudos em pesquisas com bovinos de corte (Padua et al., 2004, Prado et al., 2015a, Prado et al., 2015b, Prado et al., 2009). O uso de animais não castrados que produzem hormônios naturais é segundo Brandstetter et al. (2000) uma alternativa viável para tornar o sistema de produção mais eficiente. Os hormônios andrógenos provenientes dos testículos parecem ter maior efeito na fase em que os animais têm maior incremento de peso, proporcionado pelo melhor nível nutricional (Brandstetter et al., 2002).

Fernandes et al. (2009) trabalhando com bovinos da raça Canchim, abatidos aos 18 meses de idade em diferentes classes sexuais, encontraram que para machos inteiros, castradas e fêmeas, o percentual do gordura no Longissimus dorsi foi de 2,24\%, 2,65\% e 2,35\%, respectivamente. Já, Silva et al. (2007) comparando a força de cisalhamento da carne de novilhas castradas e não castradas obtiveram valores estatísticos idênticos. Isto demonstra que o sexo tem variação significativa para os parâmetros qualitativos da carne. Tecnicamente, há maior deposição de gordura em animais que não possuem hormônios andrógenos ou que os tem por apenas um período (fêmeas e machos castrados) em contraste com animais inteiros, os quais têm maior deposição de músculo.

\section{Idade ao abate}

O fator maturidade é comum a todos os sistemas de tipificação de carcaça bovina, porque há evidências de que a qualidade organoléptica da carne, principalmente a maciez, piora com o avanço da idade, possivelmente em decorrência de alterações que ocorrem no colágeno 
intramuscular (Luckett et al., 1975). À medida que a idade do animal aumenta as ligações entre as cadeias do colágeno são progressivamente substituídas por ligações irreversíveis e termoestáveis. Isto diminui a solubilidade do colágeno, motivo pelo qual a carne de animais mais velhos tende a ser menos macia (Lawrie, 1977). Outro fator de impacto é a deposição da gordura subcutânea, a qual começa a ser colocada antes da gordura intramuscular nas carcaças dos animais. A gordura intramuscular só é depositada a partir do momento que o animal ganha peso em taxas elevadas, ou quando avança em idade ou peso corporal. Porém, a gordura subcutânea tem importância significativa na qualidade da carcaça, sendo necessário uma quantidade mínima de gordura subcutânea $(3 \mathrm{~mm})$ que terá a função de isolante térmico durante o resfriamento. Esse isolamento evitará o encurtamento das fibras musculares, que resultaria em menor maciez da carne (Lawrie, 1977).

Smith et al. (1988) demonstraram, em carcaças de bovinos zebu norte-americanos, que enquanto a maturidade das carcaças passa de A 24 meses, para B - 42 meses, a força de cisalhamento do contrafilé maturado por 8-10 dias aumentou de 3,23 para 3,39 $\mathrm{kg}$ de força de cisalhamento (WB), os escores de sabor/aroma, maciez e aceitação pelo consumidor tiveram uma pequena redução, e a suculência não teve alteração significativa. Passando de B para C maior de 42 meses, de $\mathrm{C}$ para $\mathrm{D}$ aproximadamente 4 anos, e de D para E aproximadamente 5 anos, ocorreram sucessivos incrementos na força de cisalhamento e reduções nos escores de maciez e aceitação pelos consumidores.

\section{Nutrição}

Frigoríficos brasileiros comumente alegam falta de acabamento nas carcaças com de menos de 16 arrobas $(240 \mathrm{~kg})$. Essa falta de acabamento é um fato inegável, principalmente quando se trata de machos não castrados principalmente zebuínos. Segundo Felício (1997) para apresentar acabamento, essa classe de animal deveria ser abatida ao atingirem $500 \mathrm{~kg}$ de peso vivo no mínimo.

Medeiros et al. (1987) contrastaram os escores e opiniões entre um painel de degustadores treinados, a respeito de maciez, sabor e suculência da carne de dois grupos de bovinos jovens. Um dos grupos foi terminado durante o verão em regime de pasto irrigado, e abatido com peso médio de carcaça de $235 \mathrm{~kg}$ e $3,8 \mathrm{~mm}$ de gordura subcutânea. O outro, terminado em 100 dias de confinamento com ração de alta energia contendo $80 \%$ de concentrado, foi abatido com peso médio de $336 \mathrm{~kg}$ de carcaça, 10,9 $\mathrm{mm}$ de gordura.

Como resultado, o painel de degustadores treinados foi capaz de detectar diferenças de maciez, suculência e sabor, sempre favoráveis à carne de contrafilé do gado confinado (Medeiros et al., 1987).

\section{Fatores nutricionais que afetam a maciez da carne}

Para se avaliar a suculência de uma carne, devem-se observar duas fases, a primeira é a liberação rápida dos fluídos, a qual dá à impressão de umidade durante as primeiras mastigadas. A segunda fase é dependente da gordura, que estimula a salivação, sustentando a suculência da carne (Lawrie, 1981). Baseado nessas informações nota-se a importância da gordura intramuscular como componente qualitativo da maciez sensorial, que vai muito além da maciez objetiva detectada pelo texturômetro. Nesse contexto, a terminação em dieta com alto nível de energia, a base de grãos, por um período mínimo de 75 dias, é uma das maneiras que garantem ou ao menos melhoram a maciez da carne. Isso se deve à alta densidade energética da dieta, que por consequência antecede a deposição de gordura intramuscular.

Em outro estudo, Realini et al. (2004) apresentaram diferenças quanto às características qualitativas da carcaça dos animais terminados em confinamento ou em pastagem. Os animais terminados em confinamento tiveram carcaças mais pesadas e com maior cobertura de gordura $(3,8$ x 6,1 mm). Já Arboitte et al. (2004) trabalharam com novilhos Charolês x Nelore de dois anos de idade terminados em confinamento com diferentes pesos de abate $(425,467$ e 510 $\mathrm{kg}$ ) e observaram incrementos lineares sobre a espessura de gordura subcutânea, percentual de gordura na carcaça e marmoreio.

De acordo com Pethick et al. (2004) a deposição de gordura intramuscular aumenta de forma linear dos 200 aos $400 \mathrm{~kg}$ de carcaça. Porém, com o auxílio de algumas estratégias nutricionais, pode-se antecipar e/ou alterar o padrão de deposição de gordura intramuscular. 
Como exemplo, Vaz et al. (2005) testaram o efeito de dietas com três níveis de concentrados, associados à silagem, em novilhos terminados em confinamento dos 20 aos 22 meses de idade, com vistas a notar a qualidade da carcaça e da carne dos mesmos. O marmoreio foi similar entre os três níveis de concentrado, embora, numericamente, esta característica tenha melhorado nos níveis mais altos de concentrado oferecidos para os animais, o que poderia ocasionar diferença significativa entre os tratamentos se o período de terminação fosse mais prolongado.

Pethick et al. (2004) ressalvam que animais terminados em pastagens têm menor deposição de gordura intramuscular, quando comparados a animais terminados em confinamento. Isso se deve ao fato dos animais terminados em pastejo apresentarem menor consumo de alimentos e maior tamanho de intestino, o que leva a maior demanda de energia para mantença e menor disponibilidade de energia líquida para ganho de peso. Assim sendo, a principal forma de aumentar a deposição de marmoreio na carcaça é o fornecimento de dietas capazes de produzirem elevadas taxas de ganho de peso (Dian et al., 2009; Dian et al., 2010). Seguindo esse pensamento, o fornecimento de alimentos amiláceos pelo "creep feeding", ou abrir mão da desmame precoce com suplemento de alimentos amiláceos, seriam estratégias aconselháveis, pois estás técnicas estimulam a hiperplasia dos adipócitos intramusculares incrementando os percentuais de gordura intramuscular na carcaça (Schoonmaker et al., 2004). Por fim, dietas com altos níveis de concentrado reduzem o tempo de ruminação, estimulam em menor quantia a salivação e aumentam as taxas de fermentação ruminal. Esses fatores associados levam a uma queda no pH ruminal, e um perfil de produção de ácidos graxos diferenciado (French et al., 2000).

Eiras et al. (2014) sugeriram que, dietas com elevadas proporções de volumoso incrementam a concentração molar de ácido acético no rúmen, o qual é o principal responsável pela deposição de gordura na carcaça. Embaso em todo esse contexto, nota-se que a maciez da carne é o maior atrativo para os consumidores, sendo a idade de abate dos animais e a gordura subcutânea e intramuscular os principais fatores que interferem nessa característica (Guerrero et al., 2013).

\section{Referências bibliográficas}

Arboitte, M. Z., Restle, J., Alves Filho, D. C., Brondani, I. L., Pacheco, P. S., Menezes, L. F. G. \& Perottoni, J. (2004). Composição física da carcaça, qualidade da carne e conteúdo de colesterol no músculo Longissimus dorsi de novilhos 5/8 Nelore-3/8 Charolês terminados em confinamento e abatidos em diferentes estádios de maturidade. Revista Brasileira de Zootecnia, 33, 959-968.

Brandstetter, A. M., Pfaffl, M. W., Hocquette, J. F., Gerrard, D. E., Picard, B., Geay, Y. \& Sauerwein, H. (2000). Effects of muscle type, castration, age, and compensatory growth rate on androgen receptor mRNA expression in bovine skeletal muscle. Journal of Animal Science, 78, 629-637.

Brandstetter, A. M., Sauerwein, H., Veerkamp, J. H., Geay, Y. \& Hocquette, J. F. (2002). Effects of muscle type, castration, age and growth rate on H-FABP expression in bovine skeletal muscle. Livestock Production Science, 75, 199-208.

Crouse, J. D., Cundiff, L. V., Koch, R. M., Koohmaraie, M. \& Seideman, S. C. (1989). Comparisons of and inheritance for carcass beef characteristics and meat palatability. Journal of Animal Science, 67, 2661-2668.

Dian, P. H. M., Prado, I. N., Fugita, C. A., Prado, R. M., Valero, M. V. \& Bertipaglia, L. M. A. (2009). Replacing corn with cassava starch by-products on the performance, digestibility and carcass characteristics of bulls in confinement. Acta Scientiarum. Animal Sciences, 31, 381-387.

Dian, P. H. M., Prado, I. N., Valero, M. V., Rotta, P. P., Prado, R. M., Silva, R. R. \& Bertipaglia, L. M. A. (2010). Levels of replacing corn by cassava starch on performance and carcass characteristics of bulls finished in feedlot. Semina: Ciências Agrárias, 31, 497-506.

Eiras, C. E., Marques, J. A., Prado, R. M., Valero, M. V., Bonafé, E. G., Zawadzki, F., Perotto, D. \& Prado, I. N. (2014). Glycerin levels in the diets of crossbred bulls finished in feedlot: Carcass characteristics and meat quality. Meat Science, 96, 930-936.

FAPRI. (2015). Food and Agricultural Policy Research Institute. In: Database, W. A. O. (ed.) Food and Agricultural Policy Research 
Institute. Iowa State University and University of Missouri-Columbia Ames, IA, USA.

Felício, P. E. (1997). Fatores ante e post mortem que influenciam na qualidade da carne bovina.

Fernandes, A. R. M., Sampaio, A. A. M., Henrique, W., Tullio, R. R., Oliveira, E. A. \& Silva, T. M. (2009). Composição química e perfil de ácidos graxos da carne de bovinos de diferentes condições sexuais recebendo silagem de milho e concentrado ou cana-deaçúcar e concentrado contendo grãos de girassol. Revista Brasileira de Zootecnia, 38, 705-712.

Ferraz, J. B. S. \& Felício, P. E. (2010). Production systems - An example from Brazil. Meat Science, 84, 238-243.

French, P., Stanton, C., Lawless, F., O'riordan, E. G., Monahan, F. J., Caffrey, P. J. \& Moloney, A. P. (2000). Fatty acid composition, including conjugated linoleic acid, of intramuscular fat from steers offered grazed grass, grass silage, or concentrate-based diets. Journal of Animal Science, 78, 2849-2855.

Geesink, G. H., Kuchay, S., Chishti, A. H. \& Koohmaraie, M. (2006). $\mu$-Calpain is essential for postmortem proteolysis of muscle proteins. Journal of Animal Science, 84, 28342840.

Goll, D. E. (1992). Role of proteinases and protein turnover in muscle growth and meat quality. Proceedings-Annual Reciprocal Meat Conference of the American Meat Science Association (USA).

Guerrero, A., Valero, M. V., Campo, M. M. \& Sañudo, C. (2013). Some factors that affect ruminant meat quality: from the farm to the fork. Review. Acta Scientiarum. Animal Sciences, 35, 335-347.

Hocquette, J. F., Lehnert, S., Barendse, W., Cassar-Malek, I. \& Picard, B. (2007). Recent advances in cattle functional genomics and their application to beef quality. Animal, 1, 159-173.

Hocquette, J. F., Richardson, R. I., Prache, S., Medale, F., Duffy, G. \& Scollan, N. D. (2005). The future trends for research on quality and safety of animal products. Italian Journal of Animal Science, 4, 49-72.

Koohmaraie, M., Wheeler, T. \& Shackelford, S. (1994). Beef tenderness: regulation and prediction. Nebraska: US Meat Animal Research Center.

Lawrie, R. (1981). Developments in meat science-2. Applied Science Publishers.

Lawrie, R. A. (1977). Meat: Current developments and future status. Meat Science, $1,1-13$.

Lee, W. J., Ma, H., Takano, E., Yang, H. Q., Hatanaka, M. \& Maki, M. (1992). Molecular diversity in amino-terminal domains of human calpastatin by exon skipping. Journal of Biological Chemistry, 267, 8437-8442.

Luckett, R. L., Bidner, T. D., Icaza, E. A. \& Turner, J. W. (1975). Tenderness studies in straightbred and crossbred steers. Journal of Animal Science, 40, 468-475.

Maciel, M. V., Araújo, L. P. A., Lima Júnior, D. M., Nascimento, R. A. H. \& Freire, D. A. (2011). Métodos avaliativos das características qualitativas e organolépticas da carne de ruminantes. Revista Verde de Agroecologia e Desenvolvimento Sustentável, 6, 17-24.

Medeiros, L. C., Field, R. A., Menkhaus, D. J. \& Russell, W. C. (1987). Evaluation of rangegrazed and concentrate fed beef by a trained sensoty panel, a housedhold panel and laboratory market group. Journal of Sensory Studies, 2, 259-272.

Padua, J. T., Magnabosco, C. U., Sainz, R. D., Miyagi, E. S., Prado, C. S., Restle, J. \& Resende, L. S. (2004). Genótipo e condição sexual no desempenho e nas características de carcaça de bovinos de corte super jovens. Revista Brasileira de Zootecnia, 33, 23302342.

Pethick, D. W., Harper, G. S. \& Oddy, V. H. (2004). Growth, development and nutritional manipulation of marbling in cattle: a review. Animal Production Science, 44, 705-715.

Prado, I. N. $\left(02010^{a}\right)$. Introdução a bovinocultura de corte. In: Prado, I. N. (ed.) Produção de bovinos de corte e qualidade da carne. Eduem, Maringá, Paraná, Brasil.

Prado, I. N. (2010b). Produção de bovinos de corte e qualidade da carne. Eduem, Maringá, Paraná, Brasil.

Prado, I. N., Campo, M. M., Muela, E., Valero, M. V., Catalan, O., Olleta, J. L. \& Sañudo, C. (2015a). Effects of castration age, protein 
level and lysine/methionine ratio in the diet on colour, lipid oxidation, and meat cceptability of intensively reared Friesian steers. Animal, 9, 1423-1430.

Prado, I. N., Eiras, C. E., Fugita, C. A., Passetti, R. A. C., Ornaghi, M. G., Rivaroli, D. C., Pinto, A. A. \& Moletta, J. L. (2015b). Animal Performance and Carcass Characteristics of Bulls (1/2 Purunã vs $1 / 2$ Canchim) Slaughtered at 16 and 22 Months Old, and Three Different Weights. Asian-Australasian journal of animal sciences, 28, 612 .

Prado, J. M., Prado, I. N., Visentainer, J. V., Rotta, P. P., Perotto, D., Moletta, J. L., Prado, R. M. \& Ducatti, T. (2009). The effect of breed on the chemical composition and fatty acid profile of the Longissimus dorsi muscle of Brazilian beef cattle. Journal of Animal and Feed Sciences, 18, 231-240.

Realini, C. E., Duckett, S. K., Brito, G. W., Dalla Rizza, M. \& Mattos, D. (2004). Effect of pasture vs. concentrate feeding with or without antioxidants on carcass characteristics, fatty acid composition, and quality of Uruguayan beef. Meat Science, 66, 567-577.

Rotta, P. P., Prado, R. M., Prado, I. N., Valero, M. V., Visentainer, J. V. \& Silva, R. R. (2009). The effects of genetic groups, nutrition, finishing systems and gender of Brazilian cattle on carcass characteristics and beef composition and appearance: a review. Asian-Australasian Journal of Animal Sciences, 22, 1718-1734.

Schoonmaker, J. P., Cecava, M. J., Fluharty, F. L., Zerby, H. N. \& Loerch, S. C. (2004). Effect of source and amount of energy and rate of growth in the growing phase on performance and carcass characteristics of early- and normal-weaned steers. Journal of Animal Science, 82, 273-282.

Silva, L. A. F., Fioravanti, M. C. S. \& Prado, C. S. (2007). Características de carcaça e carne em novilhas castradas ou não-castradas da raça nelore. Ciência Animal Brasileira, 8, 777-785.

Smith, G., Berry, B., Savell, J. \& Cross, H. (1988). USDA Maturuty indices and palatability of beef rib steaks. Journal of Food Quality, 11, 1-13.

Vaz, F. N., Restle, J., Silva, N. L. Q., Alves Filho, D. C., Pascoal, L. L., Brondani, I. L. \& Kuss, F. (2005). Nível de concentrado, variedade da silagem de sorgo e grupo genético sobre a qualidade da carcaça e da carne de novilhos confinados. Revista Brasileira de Zootecnia, 34, 239-248.

Whipple, G., Koohmaraie, M., Dikeman, M. E., Crouse, J. D., Hunt, M. C. \& Klemm, R. D. (1990). Evaluation of attributes that affect longissimus muscle tenderness in Bos taurus and Bos indicus cattle. Journal of Animal Science, 68, 2716-28.

\section{Article History:}

Received 18 July 2016.

Accepted 6 August 2016.

Available online 27 September 2016

License information: This is an open-access article distributed under the terms of the Creative Commons Attribution License, which permits unrestricted use, distribution, and reproduction in any medium, provided the original work is properly cite 